\title{
Promoting Active Living in Healthy Cities of Europe
}

\author{
Johan Faskunger
}

\begin{abstract}
Local governments in Europe have a vital role in promoting physical activity in the daily life of citizens. However, explicit investment in active living has been limited. One of the four core themes for Phase IV (2003-2008) of the World Health Organization (WHO) European Healthy Cities Network (WHO-EHCN) was to encourage local governments and their partners to implement programs in favor of active living. This study analyzes the performance of network cities during this period. Responses to a general evaluation questionnaire are analyzed by content according to a checklist, and categorized into themes and dimensions. Most cities viewed "active living" as an important issue for urban planning; to improve visual appeal, enhance social cohesion, create a more sustainable transport system to promote walkability and cyclability and to reduce inequalities in public health. Almost all member cities reported on existing policies that support the promotion of active living. However, only eight (of the 59) responding cities mentioned an integrated framework specific for active living. Many efforts to promote active living are nested in programs to prevent obesity among adults or children. Future challenges include establishing integrated policies specifically for active living, introducing a larger range of actions, as well as increasing funding and capacity to make a difference at the population level.
\end{abstract}

KEYWORDS Active Living, Socio-ecological model, Healthy Cities

\section{INTRODUCTION}

The built environment of cities and neighborhoods, fewer physical demands in working lives and technological innovations have all combined to increase sedentary lifestyles in recent decades ${ }^{1-4}$, posing a major threat to public health. Nearly two thirds of adult Europeans are not physically active at levels recommended by the World Health Organization ${ }^{4}$. A review of population prevalence studies around the world by Bauman and Miller ${ }^{5}$ indicates that approximately half of the studied populations are insufficiently physically active. The public health burden is very high. Physical inactivity causes an estimated 600,000 deaths per year in Europe ${ }^{6}$. In Great Britain, for example, costs have been estimated at approximately 12 billion Euros annually - independently of the costs for overweight and obesity ${ }^{7}$.

Strong scientific evidence shows that regular physical activity (PA) promotes health-related fitness, substantially lowers rates of many chronic diseases and prevents a number of disabling medical conditions. Adults adhering to the current PA recommendation have lower rates of all-cause mortality, coronary heart disease,

Faskunger is with the Swedish National Institute of Public Health, Östersund, Sweden.

Correspondence: Johan Faskunger, Östersund, Sweden. (E-mail: johan.faskunger@proactivity.se) 
hypertension, stroke, type 2 diabetes, metabolic syndrome, colon cancer, breast cancer, and depression ${ }^{4}$. In addition, more physically active people, compared to more sedentary people, have a higher level of cardio respiratory and muscular fitness, a healthier body composition, and exhibit a biomarker profile that is more conducive to preventing cardiovascular disease and enhancing bone health ${ }^{4}$.

Clearly, there is substantial evidence which should motivate governments at all levels to promote PA and create supportive environments for active living. Traditionally, they have focused on providing information and intervening at the individual level. However, information-based interventions have not been effective in changing the sedentary trend, and individual approaches to behaviour change are usually too small scale to make a difference at the population level ${ }^{1,2,7}$. There has also been a shift in focus in the last decade towards promoting physical activity in daily life, although exercise and sports are still important components of an active lifestyle ${ }^{3}$. Other trends include introducing socio-ecological models that target a large variety of sectors and arenas at different levels of society, and an increasing emphasis on making changes to the social- and built environment to improve conditions and remove barriers to active living ${ }^{3}$.

Active living is a way of life integrating PA into daily routines, such as walking and bicycling for transportation, taking the stairs, and using recreational facilities ${ }^{3}$. Since many prerequisites of health and an active lifestyle are influenced by factors at community level, the role of local governments are vital to this process. However, investments in active living have been limited to date. Bauman and Miller ${ }^{5}$ argue that:

The potential of physical activity to contribute to the improvement of population health is under-recognised. The limited strategic development, lack of national physical activity policies, and limited commitment of resources to physical activity can be contrasted with much larger budgets for tobacco control and prevention and with substantial health sector resources allocated as a response to increases in obesity among adults and children. (p 140)

In order to provide support and leadership, the World Health Organization's European Healthy Cities Network (WHO-EHCN) seeks to engage local governments in health development processes. In recent years, the network has been instrumental in influencing efforts to plan and implement actions in favour of active living. The network emphasizes the vital importance of creating and improving the physical and social environments, as well as expanding community resources, to make a long-term and sustainable difference to public health ${ }^{8}$. During Phase IV (2003-2008), 77 cities participated in the European network, while more than 1,200 other cities take part in related national networks.

This article analyzes and summarizes the work done by member cities to plan and implement actions to promote active living/PA. The aim is to facilitate the sharing of experiences of member cities and to document "added value". The information gathered in the phase IV evaluation of the WHO Healthy Cities Network is important to improve knowledge of trends, goals and the nature of strategies and actions taken by member cities.

\section{METHODOLOGY}

This article is part of a wider evaluation of Phase IV of the WHO-EHCN. The principal research instrument was a General Evaluation Questionnaire (GEQ) sent 
to 77 member cities of the Network near the end of Phase IV in 2008. The logic underpinning this instrument - the methodology — is summarized in a companion article in this supplement by de Leeuw ${ }^{9}$. For this analysis, data was extracted from responses by $59(77 \%)$ cities in 23 countries Coordinators were asked to complete the questionnaire on behalf of the Healthy Cities partnership and the responses were ratified by a political representative.

Contextual data on the location of responding cities is summarized in the article by De Leeuw ${ }^{9}$. Other articles in this supplement analyze GEQ responses to eight dimensions of Healthy Cities' activity ${ }^{10,11}$. This article overlaps the analysis on "Healthy Urban Planning" and "Healthy Ageing", for example, covering responses to the question "How did you support older people with age-friendly urban environments?" Five questions in the GEQ relate directly to Active Living:

1. In planning your neighborhoods how did you promote walking, cycling and physical activity?

2. How does your city's active living program link to public health concerns, especially about obesity and heart disease?

3. How does your city identify and reach out to sedentary people in your population?

4. Is the active living approach incorporated into your city's plan and strategies for urban development?

5. How does your city measure and monitor levels of physical activity in the population?

A checklist was developed to analyze survey responses and to categorize actions. The checklist included the following items: (i) Actions and strategies, (ii) Approaches, (iii) Policy documents, (iv) Goals, (v) Settings/levels of actions, (vi) Actors/Organizations involved, (vii) Types of physical activity behavior, (viii) Target groups. This study used a phenomenological procedure to guide the content analysis. Responses from member cities were taken at face value and the information was analyzed inductively to explore inherent patterns. The content (the actions) was structured according to units of meaning, and later clustered into themes and dimensions, in line with the procedure outlined by Cohen and Manion ${ }^{12}$. The dimensions represented higher-order constructs and included several actions and a number of themes that emerged in the analysis.

This analysis may be limited by cities under-reporting on all the measures adopted for active living. A second limitation is the lack of detailed feedback on strategies and actions, making it difficult to develop a deeper understanding of the context and processes involved. A third limitation might be bias generated by non-completion of the GEQ by a minority of network cities. However, de Leeuw ${ }^{9}$ indicates that this is unlikely to affect the overall findings.

\section{RESULTS}

The six dimensions summarized below represent higher-order constructs and include many actions and a number of themes derived from the analysis.

\section{Type of Physical Activity Behaviour Promoted}

As outlined in Table 1, member cities promoted both behaviours related to active living and sport-related behaviours. Responses included actions aimed at facilitating 


\section{TABLE 1 Types of PA behavior promoted}

Physical activity behaviors

- Overall physical activity and active living

- Cycling for transportation

- Walking for transportation

- Recreational walking, e.g., long walks

- Recreational cycling

- Exercise and sports, e.g., gym, riding, ice hockey, team sports, running

- Outdoor leisure, e.g., fishing

- Free play

- Physical education in schools

- Rehabilitation, e.g., hydrogymnastics

walking and cycling to conduct daily errands and for transportation, as well as actions promoting walking and cycling as recreation in free time. However, many cities did not specify what type of active living behavior they were promoting.

\section{Target Groups}

Member cities described a number of target groups to promote active living, frequently citing (1) elderly and (2) disabled people, (3) children, (4) sedentary groups, and (5) citizens in deprived neighborhoods (Table 2). Many cities declined to mention any specific target group, or targeted the whole population. Others targeted "vulnerable groups" but did not elaborate.

\section{Goals and Objectives}

Member cities cited a number of goals (Table 3) for active living, walkability and cyclability. Some related to the renewal of city centres and urban open space, such as enhancing city attractiveness, visual appeal and creating human-friendly environments. These, in turn, may be important to encourage tourism and one member city argued that enhancing the attractiveness of the city might encourage new business. Other goals concerned social issues, such as fostering social cohesion and contacts,

\section{TABLE 2 Target groups cited by member cities}

Target groups

- Elderly

- Children

- Sedentary citizens

- Disabled

- Ethnic minorities

- Parents with children in trolleys

- Women

- Citizens in deprived areas

- Unemployed

- Social benefit receivers

- Worksite populations

- The whole population 


\section{TABLE 3 Goals and objectives stated by member cities}

Goals and objectives

Urban renewal

- Enhance city attractiveness

- Visual appearance

- Promote access to services and shops

Transportation

- Improve connectivity for non-motorists

- Increase mobility and accessibility

- Reduce traffic volume

- Reduce speed of motor vehicle

- Reduce noise

- Improve public transport

Sustainable development

- Promote sustainable development

- Increase the proportion of urban green areas

- Prevent climate change

- Reduce air pollution
Social issues

- "Reclaim the streets" for social events

- Foster social contacts and cohesion

- Foster social capital and democratic involvement

- Prevent segregation

- Promote equality

Active living

- Raise awareness of benefits of active living

- Raise awareness of recreational facilities

- Improve walkability and cyclability

- Promote physical activity and active living

- Improve safety

- Encourage outdoor recreation

Other

- Improve public health

- Promote tourism

- Encourage new business establishments

promoting equality, preventing segregation, and "reclaiming the streets" for social events. Regarding equality, one member wrote:

Equity exists as an explicit theme in the work of the Sports Services Centre of the city in promoting physical activity: providing special swimming hours for immigrants (Muslim women), providing reduced gym prices for everyone over 60 years and free use of public physical activity facilities for everyone over 70 .

There was also evidence of social engagement and democratic influence by trying to involve citizens in urban planning:

The local people in the districts/communities participate actively in the city planning processes for better, greener and comfortable environment. The young people are often consulted, e.g., where and what kind of skating area is the best and they are invited to the establishment [opening] of the sites.

In addition to the "universal" goals of accessibility and mobility for nonmotorists, transport-related goals included reducing traffic volume and speed, improving traffic safety and reducing noise. Specific goals for active living included raising awareness of the benefits of PA generally and the potential of existing recreational facilities in parks and neighbourhoods. Finally, there were shared climate change-related goals to promote sustainable development and reduce air pollution.

\section{Actions Cited by Member Cities}

The analysis identified a variety of actions at different levels. Overall, there was an emphasis on actions targeting the built environment, including actions to promote walkability and cyclability by improvements to the city's physical infrastructure. For 
many member cities the promotion of walking and cycling was integrated into their traffic plan, for example:

The traffic plan focuses very much on pedestrians and cyclists. There is a commissioner for cyclists and one for pedestrians. There is an intersectoral working group for the issues of pedestrians.

The results are presented according to dimensions below. Table 4 outlines examples of actions by member cities. The list of actions is not exhaustive. Rather, the aim is to describe a large variety of existing actions.

Built Environment As outlined in Table 4, the dimension built environment included the themes "Children and schools", "Parks and green structures", "Community facilities", "Urban planning", "Traffic and Safety", "Cyclability", and "walkability". Salient actions were "improving existing or building new green areas and parks" (35 measures), "investing in bicycling infrastructure" $(N=41)$, "investing in infrastructure for walking" $(N=49)$, and "providing or improving community facilities for sports or recreation" $(N=26)$. Other actions concerned traffic-calming and reducing motorized traffic $(N=22)$ and designing people-friendly urban open space $(N=20)$. Developing public transport services was also important: approximately 15 cities cited actions taken to build new or improved public transport, while nine actions concerned establishing services and shops in the vicinity.

Relatively few member cities reported actions to promote safe routes to school $(7$ actions) or designing neighbourhoods to promote active living for children. Only five actions concerned renovating or developing playgrounds, while even fewer actions to improve school yards $(N=2)$.

Social Environment The dimension social environment included the themes "community events", "community schemes and programs", "financial incentives" and "other" (see Table 4). Actions based in the social environment commonly involved schemes, activities and events organised by community groups, sport clubs or other NGOs. For the purpose of this analysis, event is defined as an activity occurring infrequently or annually, for example, a cycle-to-work day, while schemes or programs are regular or typically weekly activities, for example, exercise classes. Salient actions were "organising community schemes and programs" (21 actions), "organising community or sport events" $(N=14)$. A popular action was to close inner-city roads for traffic to organise sport events. Few member cities reported actions taken in the social environment to promote walking and cycling to school, such as a "walking school bus" $(N=4)$.

Information and Communication The dimension information and communication included the themes "media campaigns", "community campaigns", "information", "health education for adults", and "guides for mobility" (see Table 4). Information and communication-based measures included producing leaflets and newsletters (9 actions), media advertising or campaigns $(N=12)$, or other forms of community campaigns $(N=6)$. Seven cities mentioned health education for adults (lectures, workshops). Novel actions included producing road safety guides for elderly people $(N=1)$ and using social marketing principles $(N=1)$.

Other Settings The health care sector was dominant in other settings. Actions $(N=25)$ included screening, advice giving, family counselling, and exercise referral schemes 


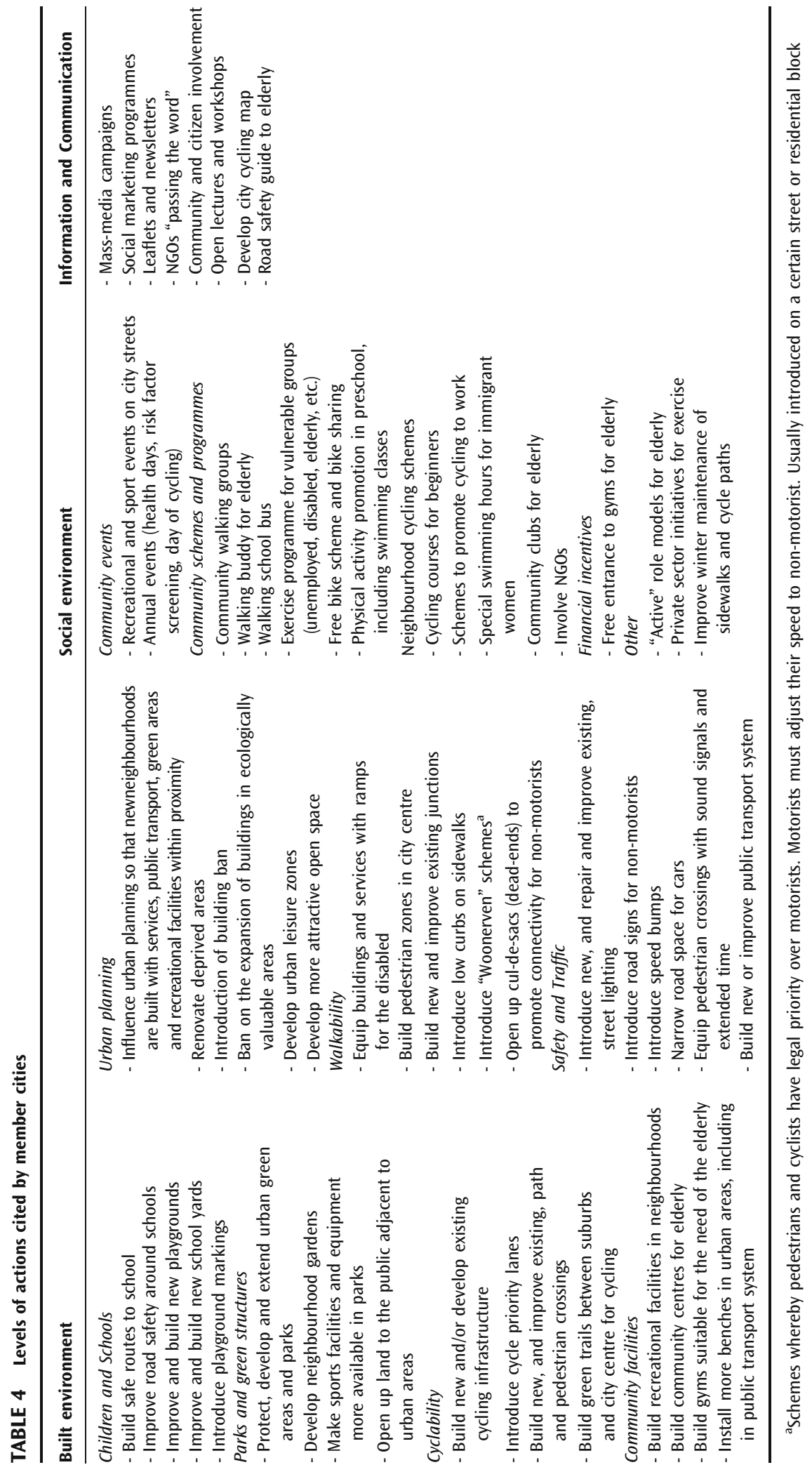


(not outlined in Table 4). Cities often cited the potential of the health care sector to identify and reach out to sedentary groups and to initiate prevention programmes for the chronically ill.

\section{BARRIERS TO ACTIVE LIVING}

Several cities experienced barriers to urban planning for active living, including difficulties in integrating health perspectives into the process of regenerating city areas, lack of funding, and pressure from other sectors of local government to allow exploitation of green areas or urban open space. Political commitment is important. One city stated:

Within the framework of physical activity the experience is that a top-down commitment to the overall agenda and an adequate funding is facilitative. Lack of these factors is an obstacle

A substantial number of cities mentioned that their work towards active living was not (yet) sufficiently integrated with other sectors or policy developments. Only eight member cities mentioned a specific integrated programme for active living. More common are frameworks or programmes tackling overweight and obesity in adults or children $(N=18)$. However, some cities mention national strategies to promote PA.

\section{EVALUATION}

Most evidence on evaluation is derived from responses to the question on how cities measure and monitor levels of PA in the population. Evaluation efforts to identify sedentary people and to evaluate the effects of interventions were mainly by household or transport surveys. Many member cities monitor citizens' participation in community schemes and social events. However, a large proportion of members $(N=28)$ did not evaluate or monitor levels of PA in the population, while one city mentioned that the national survey they used did not have sufficient sample size to analyze subgroups of citizens.

\section{DISCUSSION}

The main finding of this study is that most cities reported actions to promote active living, with emphasis on the built- and social environment. A majority of these related directly to improving walkability and cyclability, but a variety of PA behaviors were promoted (see Table 1). It is important to distinguish between different PA behaviours since they are influenced by different correlates ${ }^{2}$. Although most cities mentioned existing policy relevant for the promotion of active living, such as plans and strategies for urban development, bicycling, and sustainable development, few cities appeared to have a specific and integrated strategic framework for the promotion of active living. More common were frameworks or programs to tackle obesity in adults or children.

There were relatively few actions to promote active living among children, despite recent attention both to the societal barriers they experience ${ }^{3,13}$ and to evidence of the effectiveness of promoting PA to children through school-based interventions ${ }^{14}$. One explanation may be that schools in many countries are governed by national authorities, which make school grounds a non-issue for local governments. Another 
possibility is that investment in community playgrounds and child-friendly neighbourhoods are "hidden" under the theme "community facilities".

Cities cited a range of goals related to urban planning for active living, including: fostering social cohesion and relations, promoting mobility and accessibility, enhancing city attractiveness and appeal, promoting sustainable transport systems, and encouraging tourism. Community involvement in urban planning was cited as an example of promoting democratic influence. It seems a wise "win-win" strategy for Healthy Cities to integrate active living and public health with other important social, environmental and economic goals of local government. The potential for "win-win" approaches to achieve goals of the transport, health and environment sectors has been emphasised in a previous publication of European case studies ${ }^{15}$.

Although some cities use indicators and monitor PA by household and travel surveys, most lack thorough methodology to evaluate the effectiveness of strategies and actions. A better understanding is needed of how to promote PA in sedentary groups, and Healthy Cities must work towards providing evidence that actions taken actually promote health-enhancing PA. This finding is in line with an analysis of case studies in European countries ${ }^{15}$.

The recent popularity of socio-ecological models to promote active living is clearly evident in the scientific literature ${ }^{2,3}$. However, few cities appear to have adopted this type of model to help plan or implement actions. Only eight respondents reported having an integrated programme for active living based on assumptions about social and environmental determinants. Funding constraints (rather than lack of evidence-based knowledge) may explain why modelling is not utilised more widely. More promising for the future are many preliminary commitments to create a supportive city environment for active living, a cornerstone of socio-ecological models.

\section{Future Challenges}

This study has provided information on what member cities do well to promote active living. There are also areas for improvement. The list below outlines some of the future challenges for Healthy Cities.

(a) Cycling infrastructure between cities. One may argue that the race to invest in bicycling infrastructure within cities is about to be won, given the rate at which such infrastructure is being built. However, fewer resources are invested in building bicycling infrastructure between cities and communities. Only one network city (Belfast) specifically mentioned investing in bicycling infrastructure between two cities. The WHO Regional Office for Europe has produced evidence-based guidance for cycling infrastructure and policies ${ }^{16,17}$. The Swedish Road Administration ${ }^{18}$ has recently established a model to guide the planning of bicycling infrastructure outside communities. The conclusion was that communities within 5-15 km of each other should be connected by car-free bicycling routes $^{19}$. It may also be cost-beneficial to build cycle paths to improve accessibility to popular sites outside urban areas. Recommended distances depend on the size of the communities, the number of people living in proximity to the route, the number and use of popular sites along the route (e.g., beach, sports complex, forest, church), the potential for tourism, and whether trails can be built on disused road or train infrastructure.

(b) Improve methodology for urban planning. Another challenge is to improve methodologies for “active planning”. Geographic Information Systems (GIS) 
have high potential for identifying community needs and barriers in the environment. For example, we might look at the issue of segregation. Today, the term "segregation" is often used to refer to a whole neighborhood, mainly based on socio-economic status or some kind of an index. Many respondents indeed mentioned actions taken to create supportive environments in distinctive districts of their city. Most of those measures were probably justified in terms of impact on public health, but little is known of the segregation inherent in the physical and social structures between areas or within areas. Counter-intuitively, more affluent neighborhoods may be more segregated than poorer areas in terms of accessibility to playgrounds, sport facilities or parks.

There is a high potential to influence politics and policy by putting accessibility to active living on a geographical map. A way forward would be to geocode all address points of citizens, relevant aspects of the built environment as well as the sites and services in the city to establish accessibility among different groups to facilities and infrastructure for active living. GIS methodology can identify barriers to active living inherent in the structures of the built and natural environments, and provides the opportunity to give much more specific answers to the question: "Which citizens or which areas are segregated in terms of opportunities for an active lifestyle?"

(c) Let an ecological model guide the urban planning of parks and green structures. Building new or redeveloping existing parks and other green spaces was one of the most frequently mentioned action domains. Relatively few cities, however, appeared to have conducted baseline audits or modelled the potential impact of their strategic and operational plans. Since an important future planning issue concerns creating activity-friendly parks and green areas, it is important for Healthy Cities to improve their knowledge of how to optimize design to fulfil a variety of needs. A useful ecological model has been proposed by Bedimo-Rung et al. $^{20}$. It emphasises the importance of geographical aspects of the park and surrounding areas, and usability of the park for a variety of citizens, focusing on aesthetics, safety, maintenance, rules, and accessibility.

(d) More focus on active living for children. Relatively few cities reported actions relating to children. Factors hindering active living for children include: dangerous routes to school, densification of neighbourhoods with appropriation of children's play areas, speeding vehicles, and large increases in traffic volumes. Other factors may be lack of maintenance of school yards and community playgrounds ${ }^{2,3}$. A recent Swedish study ${ }^{21}$ using GIS methodology showed that very few children had safe routes to school for independent active travel. The share of children with safe routes to school ranged from only $3 \%$ in the least safe city (Säffle), to $36 \%$ in the safest city (Helsingborg). The magnitude of the problem is even greater when considering children's independent travel to other services in the city. The needs of children in terms of PA cannot be met by only providing special places or facilities for play, sports, and exercise. The health and development of children is influenced by their opportunities to explore their neighborhood and community. This is also an important goal in the Convention on the Rights of the Child.

(e) More resources needed. Resource constraints was one of the most frequently cited barriers to promoting active living among member cities, and it is important that funding is increased. Often the issue is how resources are distributed within the key transport sector. Certainly they are distributed unevenly to different modes of travel. Resource allocation for walking and 
bicycling transportation seldom reaches $10 \%$ of the total budget for transportation at any level, despite walking and cycling constituting a large proportion of trips in Europe every year. In Sweden, walking and cycling together receive less than $1 \%$ of the funding out of the 22-23 billion SEK annual government spending on transportation, despite approximately $30 \%$ of all trips being by foot or bicycle ${ }^{22}$. One way to increase resources for active living could be to make decision-makers more aware of the health consequences and related costs involved in travel choices and effects of governmental policies on transport and mobility. Another obstacle to overcome ${ }^{22}$ may be resistance from professionals within the transport sector itself to engage in transport planning for cycling. Health impact assessments (HIA) [24] and advocacy are likely to play important roles in making changes, but barriers exist on many levels simultaneously. Systematic analyses are needed to gain insights into what needs to be done and to secure higher funding.

\section{CONCLUSION}

Given the increasing public health burden of physical inactivity, future investments in active living will probably increase. But what will the future active city look like, and what strategies and actions will be implemented in 10 years' time? Acknowledging the promising efforts of many Healthy Cities, future active cities will probably be more successful in securing a higher share of resources. They will have an integrated strategy with goals, indicators and actions for active living and intersectoral collaboration is common. They are also likely to use HIAs at an early stage of relevant urban planning projects. Future active cities will rely on annual or bi-annual household surveys, validated against objectively measured PA, to gather important information on which groups to target for health promotion. They will use GIS methodology in the urban planning of active living to identify groups or neighbourhoods with low accessibility to active living. Community involvement is a natural step at all levels of urban planning and when implementing schemes and programmes for active living. The staff involved in the planning or implementation of actions will be regularly trained to possess the right skills and expertise needed. Evaluation is then a natural step of planning, programming, implementation and follow-up of policies, strategies and actions.

\section{REFERENCES}

1. Committee on Physical Activity, Health, Transportation, and Land Use. Does the built environment influence physical activity? Examining the evidence. 2005, Transportation Research Board/Institute of Medicine: Washington, DC.

2. Faskunger J. Den byggda miljöns påverkan på fysisk aktivitet. En kunskapssammanställning för regeringsuppdraget "Byggd miljö och fysisk aktivitet". Östersund: Statens folkhälsoinstitut; 2007.

3. World Health Organization, Regional Office for Europe. Promoting physical activity and active living in urban environments: The role of local governments. In: Edwards P, Tsouros A, editors. The solid facts series. Copenhagen, Denmark; 2006.

4. World Health Organization, Regional Office for Europe. In: Cavill N, Kahlmeier S, Racioppi F, eds. Physical activity and health in Europe: evidence for action. Copenhagen, Denmark; 2007. 
5. Bauman A, Miller Y. The public health potential of health enhancing physical activity. In: Oja P, Borms J, eds. Health enhancing physical activity: perspectives. Oxford: Meyer \& Meyer Sport; 2004: 125-148.

6. WHO, The World Health Report. Reducing risks to health, promoting healthy life. Geneva: WHO; 2002: 2002.

7. Department of Health, Physical Activity, Health Improvement and Prevention. At least five a week: Evidence on the impact of physical activity and its relationship to health. A report from the Chief Medical Officer. London, United Kingdom; 2004.

8. Ashton J. Healthy cities. Milton Keynes, UK: Open University Press; 1992.

9. de Leeuw E. Do healthy cities work? A logic of method for assessing impact and outcome of healthy cities. J Urban Health. 2012; 89(2): 217-231.

10. Barton H, Grant M. Healthy urban planning. J Urban Health. 2012. doi:10.1007/ s11524-011-9649-3.

11. Green G. Age friendly cities of Europe. J Urban Health (in press).

12. Cohen L, Manion L. Research methods in education. 4th ed. London, UK: Routledge; 1994.

13. WHO regional office for Europe, Promoting active living in and through schools. Policy statements and guidelines for action. Report of a WHO meeting. Copenhagen, Denmark; 1998.

14. van Sluijs EM MA, Griffin SJ. Effectiveness of interventions to promote physical activity in children and adolescents: systematic review of controlled trials. BMJ. 2007; 335(7622): 703.

15. World Health Organization, Regional Office for Europe. In: Dombois OT, Kahlmeier S, Martin-Diener E, Martin B, Racioppi F, Braun-Fahrländer C, eds. Collaboration between the health and transport sectors in promoting physical activity: examples from European countries. Copenhagen, Denmark; 2006.

16. World Health Organization, Regional Office for Europe. In: Cavill N, Kahlmeier S, Rutter H, Racioppi F, Oja P, eds. Economic assessment of transport infrastructure and policies. Methodological guidance on the economic appraisal of health effects related to walking and cycling. Copenhagen, Denmark; 2007.

17. World Health Organization, Regional Office for Europe. In: Rutter H, Cavill N, Dinsdale H, Kahlmeier S, Racioppi F, Oja P, eds. Health economic assessment tool for cycling (HEAT for cycling). User guide, version 2. Copenhagen, Denmark; 2008.

18. Kågeson $P$, Vägverket. Modell för regional inventering och planering för cykelvägar. Borlänge: Vägverket; 2007.

19. Kågeson P. Modell för regional inventering och planering av cykelvägar. Borlänge: Nature Associates Vägverket; 2007.

20. Bedimo-Rung AL, Mowen AJ, Cohen DA. The significance of parks to physical activity and public health: a conceptual model. Am J Preventive Med. 2005; 28(2 Suppl 2): 159168.

21. Reneland M. Tillgänglighetsvillkor $i$ svenska städer - TWISS. Borlänge: Vägverket; 2004.

22. Ison E. The introduction of health impact assessment in the WHO European Healthy Cities Network. Health Promotion Int. 2009; 24(suppl 1): 64-71. 